\title{
Jorge Luis Borges e Peter Eisenman, Narrativa e Arquitetura
}

\section{Andrés Martín Passaro}

Resumo

O trabalho pretende fazer uma análise comparativa entre as obras do escritor Jorge Luis Borges e do arquiteto Peter Eisenman. Para isto foram escolhidas La casa de Asterión que nada mais é que um conto do livro El Aleph de Borges' e Guardiola House ${ }^{2}$, uma casa do arquiteto Eisenman.

A idéia do trabalho é encontrar uma analogia entre ambas produções, e surgiu a partir da leitura da crítica aos trabalhos de Peter Eisenman, em que comparecem indicações de similitude entre o pensamento deste arquiteto e o do escritor.

Procurou-se fazer leitura de Borges em vários de seus livros passando por textos do tipo "labirínticos ou abissais" (como observou Otilia Arantes... ${ }^{4}$ ).

\section{Abstract}

This study intends to make a comparison between the works of the writer Jorge Luis Borges and of the architect Peter Eisenman. For this purpouse, there were selected "La casa de Asterión" a tale from Borges' book "El Aleph" and the "Guardiola House" a Peter Eisenman's project.

The purpose is to look for an analogy between these two works. This idea came out from reading the criticals about Eisenman's works, which pointed out that some similiraty between the architect's thoughts and the writer one's could be noticed.

La casa de Asterion was chosen after passing through many "labyrinthic and abyssals'" texts (as stated Otília Arantes).
Aluno de mestrado - FAUUSP

(1) BORGES, Jorge Luis. La casa de Asterión. In: El Aleph. Buenos Aires: Emecé, 1949.

(2) EISENMAN, Peter. Guardiola House. In: Deconstruction. New York: 1989, e Revista $A+U$ 220-223, 1989.

(3) Cf. também: de Jorge Luis Borges. "There are more things !" Ellibrode Arena, 1975; e "El inmortal" El Aleph. Op. Cit.

(4) ARANTES, Otllia Beatriz Fiori de. "Margens da arquitetura". O lugar da arquitetura depois dos modernos. Sāo Paulo: Edusp/Studio Nobel, 1993. 


\section{Introdução}

A relação entre o pensamento de Borges e Eisenman tem sido apontada em textos de autores contemporâneos. Estes, entretanto, se limitam a mencionála, sem um desenvolvimento aprofundado do tema, criando assim uma situação que despertou o interesse pela pesquisa deste assunto.

Um dos autores a tocar nesta similitude entre a obra de Borges e de Eisenman é Otília Arantes quando afirma sobre a arquitetura de Peter Eisenman: 'Como resultado - se é que se pode falar assim -, ao contrário de volumes fechados, uma arquitetura em abismo, labiríntica (na mesma época a nova crítica literária francesa reinventava Borges), espaços inconclusos, formas sem função, quando muito destinadas a provocar no observador um sentimento de estranheza ${ }^{5}$ A autora não comenta o assunto de nenhuma maneira, mas despertou 0 interesse pelo tema.

Um outro autor que relaciona o pensamento de Eisenman ao de Borges é Josep Maria Montaner ${ }^{6}$ quando classifica este arquiteto na posição "nueva abstracción formal" juntamente com Bernard Tschumi e John Hejduk. Estes últimos propunham aos seus estudantes a criação de espaços a partir da leitura de Jorge Luis Borges, Marcel Proust, Thomas Hardy e outros.

O conto de Borges foi escrito em 1949, e é anterior às teorias de Eisenman. Lembremos que as primeiras casas do arquiteto datam de 1967, juntamente com os seus primeiros escritos ${ }^{7}$ Arantes coloca ainda que a crítica "reinventava" Borges, pressupondo algum tipo de releitura do trabalho deste. A casa Guardiola começou a ser construída no fim de 1988, quase 20 anos depois dos primeiros escritos de Eisenman, podendo ser considerada como uma postura já amadurecida do arquiteto.

Este trabalho pretende fazer uma análise comparativa de obras dos dois autores - por um lado um trabalho literário, por outro um arquitetônico - traçando uma analogia a partir de alguns pontos em comum entre eles; e considerando como instrumento de trabalio "o sujeito" 'o tempo" e "o espaço"

Para efeito de análise, serão utilizados a versão portuguesa do conto "La casa de Asterión"8, e os desenhos da "Guardiola House"9

\section{O Conto de Borges}

\section{A casa de Asterión}

(5) Ibidem.

(6) MONTANER, Josep Maria. Después del Movimiento Moderno, Arquitectura de la segunda mitad del siglo XX. capítulo XVII La nueva abstracción formal, p. 246, Barcelona: Gustavo Gili, 1993.

(7) Cfr AAW. Five architects. Gustavo Gili.

(8) BORGES, Jorge Luis. O Aleph. Editora Globo: 1977.

(9) EISENMAN, Peter. Deconstrution, Op. cit.

(10) O original diz quatorze, mas sobram motivos para inferir que, na boca de Asterion, esse adjetivo numeral vale por infinitos.
E a rainha deu a luz um filho que se chamou Asterión. APOLODORO: Biblioteca, III, I.

Sei que me acusam de soberba, e talvez de misantropia, e talvez de loucura. Tais acusações (que eu castigarei no devido tempo) são irrisórias. É verdade que não saio de casa, mas também é verdade que as suas portas (cujo número é infinito) ${ }^{10}$ estão abertas dia e noite aos homens e também aos animais. Que entre quem quiser. Não encontrará pompas femininas nem o bizarro aparato dos palácios, mas sim a quietude e a solidão. P . . há outra na face da terra. (Ment zarecida no Egito.) Até meus detratores adm 
afirmação ridícula é que eu, Asterión seja um prisioneiro. Repetirei que nẳo há uma porta fechada, acrescentarei que não existe uma fechadura? Mesmo porque num entardecer pisei a rua, se voltei antes da noite, foi pelo temor que me infundiram os rostos da plebe, rostos descoloridos e iguais, como a mão aberta. O soljá se tinha posto, mas o desvalido pranto de um menino e as preces rudes do povo disseram que me haviam reconhecido. O povo orava, fugia, se prosternava; alguns se encarapitavam no estilobato do templo das Tochas, outros juntavam pedras. Algum deles, creio, se ocultou no mar. Não é em vão que uma rainha foi minha mãe; não posso confundir-me com o vulgo, ainda que o queira minha modéstia.

$O$ fato é que sou único. Não me interessa o que um homem possa transmitir a outros homens; como filósofo, penso que nada é comunicável pela arte da escrita. As enfadonhas e triviais minúcias não encontram espaço em meu espírito, capacitado para o grande; jamais guardei a diferença entre uma letra e outra. Certa impaciência generosa não consentiu que eu aprendesse a ler. Às vezes o deploro, porque as noites e os dias são longos.

Claro que não me faltam distraçōes. Como o carneiro que vai investir, corro pelas galerias de pedra até cair no chão, estonteado. Oculto-me à sombra de uma cisterna ou à volta dum corredor e divirto-me com que me busquem. Há terraços donde me deixo cair, até ensangüentar-me. A qualquer hora posso fazer que estou dormindo, com os olhos cerrados e a respiração contida. (Às vezes durmo realmente, às vezes já é outra a cor do dia quando abro os olhos.) Mas, de todos os brinquedos, o que prefiro é o do outro Asterión. Finjo que ele vem visitar-me e que eu lhe mostro a casa. Com grandes reverências Ihe digo: Agora voltamos à encruzilhada anterior ou Agora desembocamos em outro pátio ou Bem dizia eu que te agradaria o pequeno canal ou Agora vais ver uma cisterna que se encheu de areia ou Já vais ver como o porão se bifurca. Às vezes me engano e rimo-nos os dois amavelmente.

Não tenho pensado apenas nesses brinquedos; tenho também meditado sobre a casa. Todas as partes da casa existem muitas vezes, qualquer lugar é outro lugar. Não há uma cisterna, um pátio, um bebedouro, um pesebre; são quatorze [são infinitos] os pesebres, bebedouros, pátios, cisternas. A casa é do tamanho do mundo; ou melhor é o mundo. Todavia, de tanto andar por pátios com uma cisterna e poeirentas galerias de pedra cinza alcancei a rua e vi o templo das Tochas e o mar. Não entendi isso até uma visão noturna me revelar que também são quatorze [infinitosl os mares e os templos. Tudo existe muitas vezes, quatorze vezes, mas duas coisas há no mundo que parecem existir uma só vez: em cima o intrincado sol; embaixo, Asterión. Talvez eu tenha criado as estrelas e o sol e a enorme casa, mas já não me lembro.

A cada nove anos, entram na casa nove homens para que eu os liberte de todo mal. Ouço seus passos ou sua voz no fundo das galerias de pedra e corro alegremente a buscá-los. A cerimônia dura poucos minutos. Um após outro caem sem que eu ensangrente as mãos. Onde caíram, ficam, e os cadáveres ajudam a distinguir uma galeria das outras. Ignoro quem sejam, mas sei que um deles, na hora da morte, profetizou que um dia vai chegar meu redentor. Desde então a solidão não me magoa, porque sei que meu redentor vive e que por fim se levantará do po. Se meu ouvido alcançasse todos os rumores do mundo, eu perceberia seus passos. Oxalá me leve para um lugar com menos galerias e menos portas. Como será meu redentor? - me pergunto. Será um touro ou um homem? Será talvez um touro com cara de homem? Ou será como eu? 
E o sol da manhã rebrilhou na espada de bronze. Já não restava qualquer vestígio de sangue.

- Acreditarás, Ariadna? - disse Teseu -. O minotauro apenas se defendeu.

Para Marta Mosqueira Eastman.

\section{Análise do conto}

\section{0 sujeito}

A primeira impressão que temos logo depois de ler o conto é que fomos enganados. Pelo menos no desenvolver da história, porque o Asterión era nada menos que o famoso Minotauro, que nos foi apresentado na sua verdadeira identidade unicamente nas quatro (4) últimas palavras do conto. Esta situação nos demonstra o total desinteresse pelo sujeito (pelo menos o verdadeiro), já que sendo um personagem muito conhecido, Borges poderia tirar mais proveito disto. Mas parece que "o sujeito" "o oficial" não interessa, ele é, na realidade, negado até a última instância. Borges inventa deste modo um novo personagem, "o outro", do qual nós não temos as referências suficientes para poder identificar a verdadeira história que está sendo narrada.

Um outro personagem que é distorcido é Teseu, apresentado como o redentor de Asterión, ou, em outras palavras, o salvador do Minotauro. Isto é no mínimo um paradoxo, porque, se imaginamos um redentor, sem dúvida é o salvador de Asterión, e nunca seu assassino. Desta maneira Borges trabalha o seu conto com ausência do sujeito real e a presença do fictício.

\section{O tempo}

A ausência de sujeito real é acompanhada de uma ausência de tempo real. Não podemos esquecer que esta lenda do Minotauro tem mais de 2.000 anos, e surgiu na Antigüidade Clássica, da qual nenhuma referência é dada. Borges nega essa Antigüidade Clássica utilizando todas as artimanhas possíveis para não identificá-la, negando assim o tempo real em que aconteceu a lenda.

Um outro maneirismo, para confundir a noção temporal, é utilizado nos tempos verbais da narrativa. O conto curiosamente começa sendo narrado no presente por Asterión, e acaba sendo narrado também no presente pelo Teseu, o que nos dá a impressão que a temporalidade da história é deixada de lado em favor da importância exata de cada momento da narração. Cria-se, assim, uma outra história, a história paralela, com um novo tempo que não pode ser muito bem identificado, porque é contado no presente, aconteceu no passado, mas na verdade poderia muito bem se tratar da história de um Blade Runner num futuro longínqüo.

\section{O espaço}

Um outro aspecto interessante do conto é o espaço, onde a não-referência continua sendo a fórmula. Uma clara intenção de Borges é o simulacro. Ele simula a casa de Asterión quando na realidade se trata de seu próprio labirinto. Sem dúvida que a intenção aqui continua sendo a de nos confundir, intenção que se verifica em várias outras partes do conto. Desta maneira Borges muda e falsifica a verdadeira identidade dos objetos. Um labirinto nunca poderia ser confundido com uma casa. 
Com as portas utiliza a mesma receita, dizendo que elas permanecem abertas dia e noite e, ainda, não possuem fechaduras, quando na realidade estas fechaduras não existem porque tampouco as ditas portas existem. No labirinto há sim entradas e saídas, mas não portas.

Asterión conta que todos os lugares aparecem muitas vezes, que são infinitos, situação que nos confunde porque nos faz pensar em outra dimensão da realidade, já que no nosso mundo todo é mensurável. Também diz que qualquer lugar é um outro lugar, o que nos dá a idéia ou que todos os lugares são iguais, ou bem que não há lugares a serem reconhecidos ou identificados.

\section{A obra de Peter Eisenman}

A análise da casa de Peter Eisenman vai ser feita através dos desenhos de representação desta obras, e de textos teóricos do autor.

\section{O sujeito}

A leitura do sujeito poderia ser começada a partir da negação deste. Poderíamos dizer que não existe uma contemplação de diferentes culturas. No caso da casa, temos que considerar que é uma casa à beira-mar em Cadiz (local de cultura portuária muito forte). Também não ocorre a preocupação de um "homem tipo" como nos preceitos do movimento moderno. Eisenman não está interessado na ergometria, nem na funcionalidade dos seus espaços, o que implica em não estar preocupado com o homem como sujeito.

O que o interessa é o valor autônomo dos objetos, e não o sujeito. Para Montaner (op. cit.), Eisenman herda do pós-estruturalismo o anti-humanismo, e cita uma frase de Claude Lévi-Strauss" ${ }^{11}$ que ilustra este pensamento: "O mundo começou sem o homem e acabará sem ele" definindo a condição efêmera do homem. Desta maneira, sendo o homem um simples passageiro deste mundo, para que se preocupar com ele? O objetivo da sua obra é a obra em si, e não o sujeito. Desta maneira, Eisenman, ao igual que Borges, nega o sujeito, o verdadeiro, propondo espaços cuja única razão de ser são os próprios espaços, suas formas e os seus desenvolvimentos.

Não sendo mais o homem o centro do universo, Eisenman ataca a noção de centralidade: pode ser muito bem observada a idéia labiríntica "dos caminhos que se bifurcam "12 e que negam o centro. Desta maneira, se explica o partido da casa em forma de $L$ porque o "éle" não representa em nenhum aspecto a centralidade, tão depreciada por Eisenman.

O trabalho de Eisenman ataca as formas tradicionais de ocupação do espaço pelo homem. Assim ele se preocupa em diferenciar-se desta maneira de ocupação tradicional. Em uma das suas casas ele coloca uma coluna no meio de um dormitório, e diz à este respeito: "ter uma coluna no meio do quarto de maneira a não se poder aí colocar uma cama, certamente atacará a noção de como você ocupa um quarto"13 Ora, esta visão anti-humanista sem dúvida pōe em jogo o verdadeiro papel do homem como intérprete da obra, igual ao conto de Borges, em que esses personagens não são os personagens tradicionais, e sim "os outros" Desta maneira Eisenman está à procura desses outros, para assim fazer uma nova maneira de interpretação dos espaços.
(11) LÉVI-STRAuSS, Claude. Tristes Trópicos. Argentina: Editora Universidad de Buenos Aires, 1970.

(12) BORGES, Jorge Luis. Laberinto. In: Elogio de la sombra. (1969). No habrá nunca una puerta. Estás adentro/Y el alcázar abarca el universo/Y no tiena ni anverso ni reverso/ $\mathrm{Ni}$ extremo muro $\mathrm{ni}$ secrteto centro./ No esperes que el rigor de tu camino/ Que tercamente se bifurca en otro,/ Que tercamente se bifurca en otro,/ Tendrá fin. Es de hierro tu destino/ Como tu juez. No aguardes la embestida/ Del toro que es un hombre y cuya entraña/ Forma plural da horror a la maraña/ De interminable piedra entretejida./ No existe. Nada esperes. Ni siquiera/ En el negro crepúsculo la fiera.

(13) Cfr. An Architectural Design Interview by Charles Jencks. In: Deconstruction, Op. cit. 


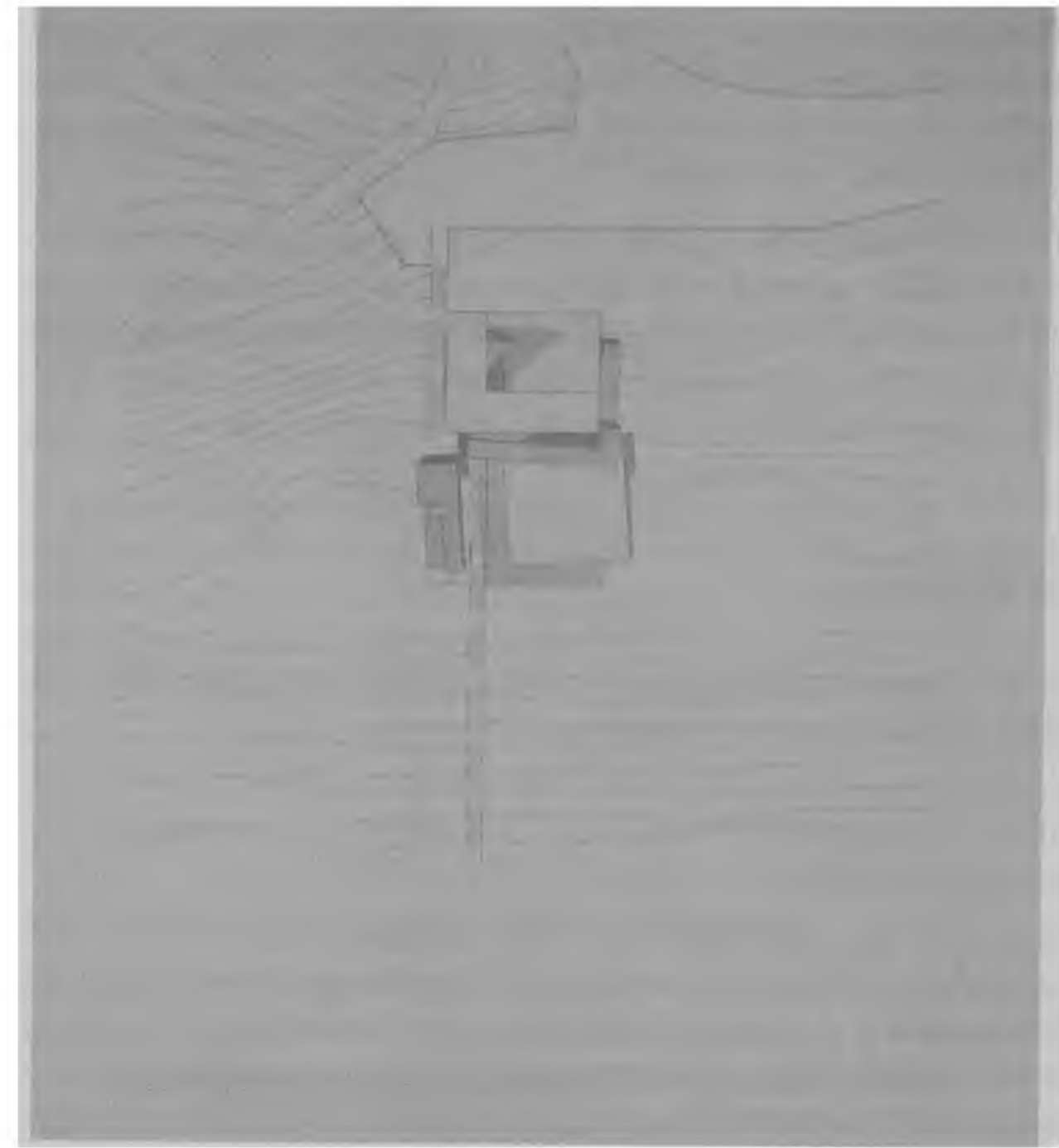



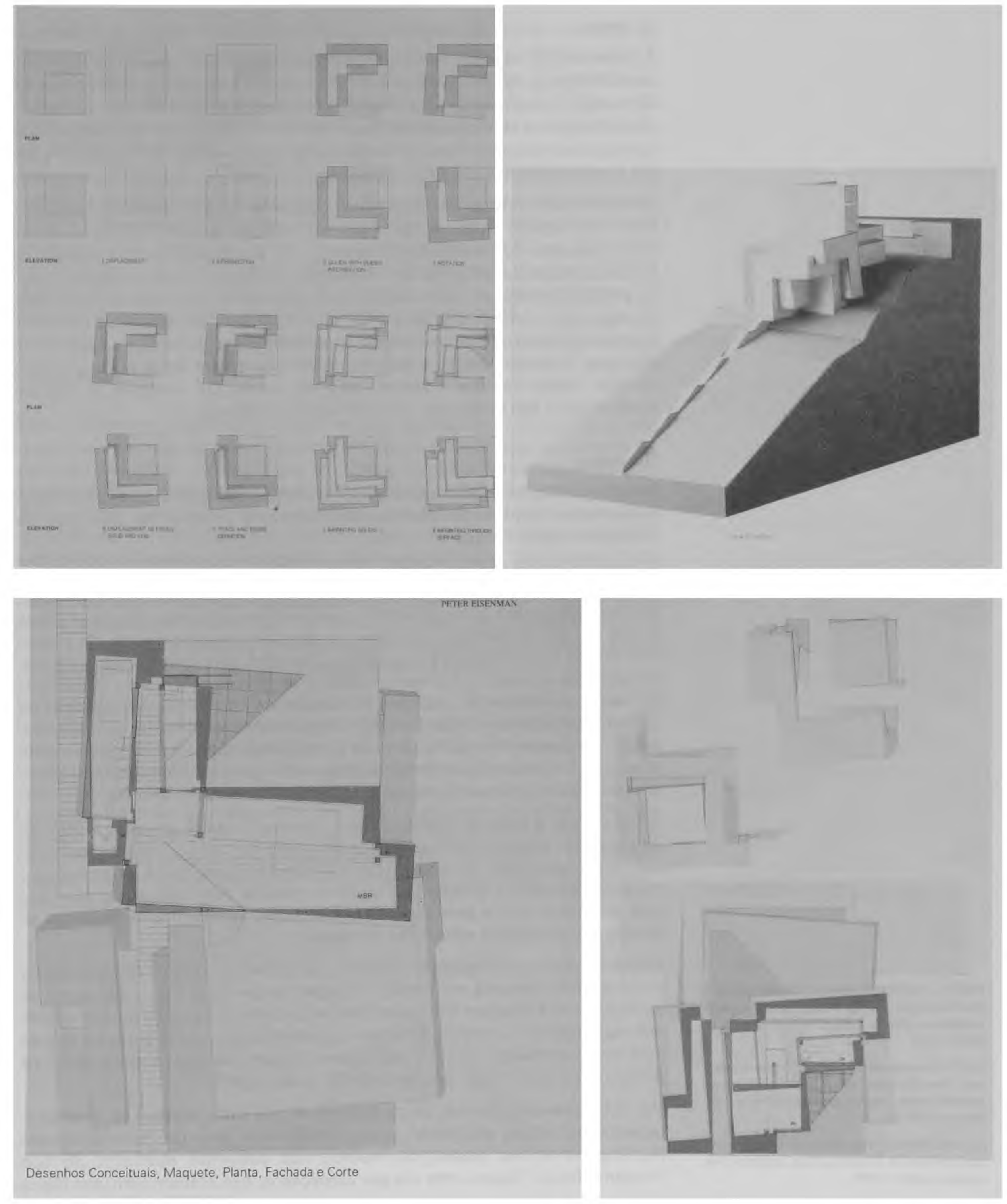


\section{O tempo}

Ao contrário do ocorrido na leitura de Borges, fica muito mais difícil fazer uma leitura temporal da obra. Podemos dizer que ela não tem intenção de representar um tempo, no sentido de uma Antigüidade Clássica. Podemos dizer que existe uma intenção de atemporalidade, no sentido de não referenciar a sua arquitetura com as obras históricas. Para Eisenman a arquitetura vale por si mesma, pelo que ela é, e não pelo que ela quer representar.

Desta maneira detectamos essa atemporalidade, de não querer ser passado. Para ele a história é uma simulação de eternidade ${ }^{14}$, porém sem preocupação com o presente nem com o futuro. Assim, pode ser observada uma negação da história, porque ele não utiliza uma linguagem histórica, nem de arquétipos, nem de estudos tipológicos, e nem sequer dos fundamentos da arquitetura moderna, situação que o enquadraria dentro de uma arquitetura de vanguarda inovativa. Isto não quer dizer que ele desconheça a história, muito pelo contrário. Igualmente a Borges, Eisenman se utiliza dela muito bem para poder elaborar a sua própria história. Neste sentido a história não lhe serve. Os símbolos e códigos estabelecidos são rejeitados, e ele reinventa os próprios.

\section{O espaço}

Sem dúvida todo o conteúdo da casa pode ser encontrado a partir da decomposição formal desta (lembremos que Montaner chama a corrente de Eisenman de "Nova Abstração Formal").

A primeira impressão que temos ao observar a maquete da casa le que é característica de toda a obra dele) é de uma total instabilidade da construção, simulando desafiar a lei de gravitação universal. Desta maneira, Eisenman nega as leis básicas da natureza. Esta idéia de desafio vai acompanhada, de acordo com ele, de uma mudança do paradigma mecânico para o eletrônico. Para ele, antigamente a arquitetura deveria parecer estável, mas hoje, com o domínio da natureza pelo homem, e o domínio do paradigma eletrônico, esta simulação de estabilidade não tem mais sentido ${ }^{15}$. Seguindo esta linha de pensamento, podemos observar no corte da casa um sistema estrutural completamente diferente dos sistemas convencionais (coluna, viga, laje), apresentando assim uma solução muito ousada, sem as referências habituais do projeto.

Sobre o lugar, a idéia de Asterión de que "qualquer lugar é um outro lugar" se repete aquie na maioria dos desenhos de Eisenman, nunca existindo a preocupação com a representação do lugar. Assim, observamos em todas as ocasiōes o desenho dos objetos isolados, indicando no máximo, os limites do terreno. Isto está de acordo com o pensamento de Eisenman, voltado à uma mudança de paradigma, sobre uma nova visão do mundo.

Ele afirma que na Antigüidade Clássica "os romanos" assim como qualquer

(14) Cfr. EISENMAN, Peter. O fim do clássico. O fim do começo. O fim do fim. In: Malhas, escalas, e dobras na obra de Peter Eisenman. São Paulo: MASP, 1993.

(15) Cfr. Uma arquitetura do caos: Uma entrevista com Peter Eisenman por Nicolau Sevcenko. In: Malhas, escalas, rastros e dobras na obra de Peter Eisenman. Op. cit.

(16) EISENMAN, Peter. Guardiola House, Santa Maria del Mar. In: Deconstruction. London: WAA Academy edition, 1989. povo, tinham interesse em marcar "o lugar" e que essa marca (ou lugar) os situava frente à natureza selvagem. Mas atualmente esta visão do mundo não tem mais sentido. A natureza está hoje dominada pelo homem, porque o mundo está completamente marcado por lugares. Assim ele não vê mais razão na preocupação como lugar, propondo então o não-lugar ${ }^{16}$.

Um outro pressuposto que utiliza Asterión é que são "infinitos os pesebres, bebedouros, pátios, cisternas" (especialmente nas casas), ou "metamorfoses" Estes, uma vez
Eisenman is do tipo uma lógica 
de produto terminado, mas sim em uma parada arbitrária nesse processo de metamorfoses infinitas ${ }^{17}$ Os espaços são quase que incompreensiveis para a mente humana. Podemos observar isto nas plantas, fachadas e perspectivas, onde este jogo de infinitos, de espaços incompreensíveis, de labirintos, e de cortes que parecem plantas e vice-versa, nos induz a uma nova maneira de compreensão do espaço.

Igualmente a Borges, quando este desvenda no final do conto a verdadeira identidade e com isto nos obriga a voltar ao desenvolvimento do conto, Eisenman também utiliza este recurso em sua obra: começamos pelo seu desenvolvimento (metamorfoses), lemos os cortes, as plantas, e só quando vemos a obra construída (ou a maquete neste caso) é que temos noção da proposta. Seu sentido real, porém unicamente é compreensível quando voltamos ao entendimento do processo, da mesma maneira que no conto.

\section{Conclusões}

A leitura do texto e das obras, e a interpretação destes, nos dá uma sensação de ausências. Ausência de sujeito real, de tempo real, e de espaço real, parecendo que tudo não passa de uma ficção ou uma simulação. Estes elementos são negados na sua verdadeira concepção. Tanto Borges como Eisenman dão a eles um novo significado, elaborando assim uma outra história diferente da que nós conhecemos. "A história paralela". com um sujeito diferente, um tempo diferente e um espaço diferente, e que ninguém a não ser eles próprios, conceberam. Este tipo de leitura coloca conto e obra como uma situação imaginária dos autores: a casa de Asterión é vista como uma cidade, uma cidade que limita externamente com o Templo das Tochás e com os mares, e, internamente, com o infinito e o incompreensível. As obras de Eisenman são vistas como a concretização dessa cidade imaginária, mas uma concretização também textual.

Esta situação nos dá a idéia de uma negação dos fatos reconhecíveis, o que nos leva, no caso de Borges, a uma releitura do texto quando a verdadeira identidade dos personagens é descoberta no final. Isto origina um interesse maior no desenvolvimento da narrativa e uma reinterpretação desta. Seria bem diferente se $o$ conto acabasse da seguinte maneira: "nem acreditarás - disse 0 redentor - Asterión nem sequer se defendeu' Este caso sem dúvida não nos levaria a essa releitura do texto, o que também ocorre com os desenhos de Eisenman. Pelos desenhos se chega ao produto final, e quando se descobre 0 produto final, torna-se imprenscindível uma releitura dos desenhos "conceituais" originadores deste.
(17) Cfr. ARANTES, Otliia. Op. cit. 1993. 